\title{
VARIATION IN THE MODE OF ORIGIN AND LEVEL OF FORMATION OF NERVE TO MEDIAL AND LATERAL HEAD OF GASTROCNEMIUS MUSCLE
}

\author{
Sharma S ${ }^{1}$, Khullar $\mathrm{M}^{2}$, Wadhwa $\mathrm{A}^{3}$, Kaur K ${ }^{4}$, Bhardwaj $\mathrm{S}^{5}$, Sharma $\mathbf{N}^{6}$. \\ ${ }^{1}$ Associate Professor, Anatomy, PIMS Jalandhar, Punjab, India. \\ ${ }^{*}$ Associate Professor, Anatomy, GGS Medical College, Faridkot, Punjab, India. \\ ${ }^{3}$ Professor - Anatomy, PIMS Jalandhar, Punjab, India. \\ ${ }^{4}$ Assistant Professor, Department of Anatomy, PIMS Jalandhar, Punjab, India. \\ ${ }^{5}$ Medical Officer, Department of Microbiology, JBMM Civil Hospital, Amritsar, Punjab, India. \\ ${ }^{6}$ Assistant Professor, Department of Pathology, SGRDIMSR, Amritsar, Punjab, India. \\ ABSTRACT
}

\begin{abstract}
Variations of nerve are not only of anatomic and embryological interest but also of clinical importance. Their adequate knowledge certainly help in increasing surgical precision and decreasing morbidity. In present study variations in mode of origin and level of formation of nerve to medial and lateral head of gastrocnemius was studied. The material for the present study comprised of 60 lower extremities belonging to 30 adult human cadavers obtained from Department of Anatomy, PIMS, Jalandhar. Neurectomy of nerve to medial gastrocnemius muscle is used to reduce volume of the muscle. For facial reconstruction after total parotidectomy, the facial nerve is being reconstructed by using vascularized sural nerve with free lateral gastrocnemius muscle flap.

KEY WORDS: Variation, Nerve To Gastrocnemius, Neurectomy, Facial Reconstruction.
\end{abstract}

Corresponding Author: Dr. Meenakshi Khullar, Associate Professor, Department of Anatomy, GGS Medical College, Faridkot, Punjab, India. Ph: 9888104425

E-Mail: meenakshikhullar8@gmail.com

Access this Article online

Quick Response code

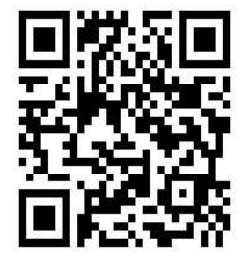

DOI: $10.16965 /$ ijar.2019.346

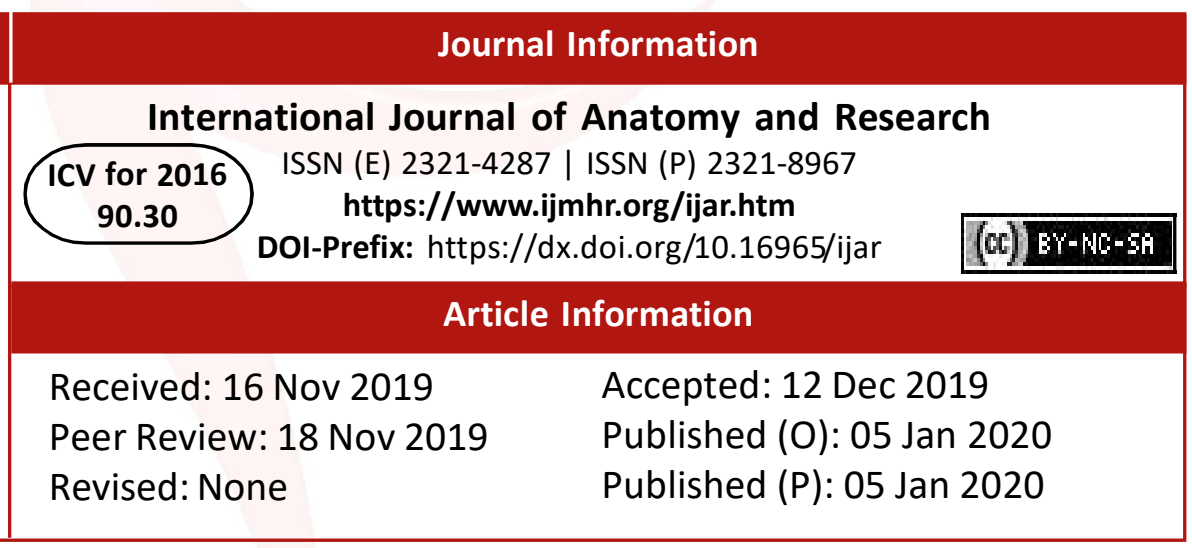

\section{INTRODUCTION}

Gastrocnemius is the most superficial muscle of the posterior compartment and forms the 'belly' of the calf. It arises by two heads, connected to the condyles of the femur by strong, flat tendons. The medial larger head is attached to a depression at the upper and posterior part of the medial condyle behind the adductor tubercle and to a slightly raised area on the popliteal surface of the femur just above the medial condyle. The lateral head is attached to a recognizable area on the lateral surface of the lateral condyle and to the lower part of the corresponding supracondylar line. Both heads also arise from subjacent areas of the capsule of the knee joint. The tendinous attachments expand to cover the posterior surface of each head with an aponeurosis, from the anterior surface of which the muscle fibres arise. The fleshy part of the muscle extends to about midcalf. The muscle fibres of the larger medial head extend lower than those of the lateral head. As the muscle descends, the muscle fibres begin to insert into a broad aponeurosis that develops 
on its anterior surface; up to this point the muscular masses of the two heads remain separate. The aponeurosis gradually narrows and receives the tendon of soleus on its deep surface to form the calcaneal tendon. Occasionally the lateral head, or the whole muscle, is absent. A third head, arising from the popliteal surface of the femur, is sometimes present. Gastrocnemius is the chief plantar flexor of the foot and it also flexes knee [1].

Each head of gastrocnemius is supplied by its own sural artery. These arteries are branches of the popliteal artery, and arise at variable levels, usually at the level of the tibiofemoral joint line. The medial sural artery almost always arises more proximally than the lateral: the medial may arise proximal to the joint line, the lateral sometimes distal to the line. Each sural artery enters the corresponding muscle head with its nerve of supply, the pedicle entering the muscle near its axial border at the level of the middle of the popliteal fossa. Medial or lateral gastrocnemius musculocutaneous flaps may be raised, each based on its neurovascular pedicle. Minor accessory sural arteries arise from the popliteal or from the superior genicular vessels [1]

Gastrocnemius is innervated by the tibial nerve, S1and S 2. Gastrocnemius is tested by plantar flexion of the foot against resistance, in the supine position and with the knee extend [1].

\section{MATERIALS AND METHODS}

The material for the present study comprised of 60 lower extremities belonging to 30 (well embalmed) adult human cadavers of known sex obtained from the Department of Anatomy, PIMS, Jalandhar. Skin incision was made from apex of popliteal fossa till the level of tibial tuberosity. Then the superficial fascia was stripped from deep fascia starting proximally. Deep fascia from posterior surface of popliteal fossa was stripped off and the fat from its upper angle was removed to expose the tibial nerve. This nerve was followed downwards. The muscular branches to gastrocnemius arose near the middle of fossa. The heads of gastrocnemius were separated and these branches were followed as far as possible. Then the deep fascia was reflected. Bellies of gastrocnemius were identified and were lifted from underlying soleus. Medial and lateral heads of gastrocnemius were cut carefully, preserving their nerve supply. Skin incision was extended downwards to the insertion of the muscle as calcaneal tendon [2].

\section{OBSERVATIONS}

Nerve to medial head of gastrocnemius

Number: In the present study, the nerve to medial head of gastrocnemius was extremely variable in number. It was evident that in majority of instances i.e. 34 (56.67\%) limbs (18 on right and 16 on left) the muscle received single twig. It was 2 in 20 (33.33\%) limbs (8 on the right and 12 on the left). In 6 (10\%) limbs (4 on the right and 2 on the left side), the number is 3.

Table 1: Percentage distribution of number of Ns. to medial head of gastrocnemius (G).

\begin{tabular}{|c|c|c|c|}
\hline \multirow{2}{*}{\begin{tabular}{c}
\multirow{2}{*}{$\begin{array}{c}\text { No. of } \\
\text { nerves }\end{array}$} \\
\cline { 2 - 4 }
\end{tabular}} & \multicolumn{3}{|c|}{ No. of limbs with particular no. of Ns. [n (\%)] } \\
\cline { 2 - 4 } & Right & Left & Total \\
\hline 1 & $30(100 \%)$ & $30(100 \%)$ & $60(100 \%)$ \\
\hline 2 & $18(60.00 \%)$ & $16(53.33 \%)$ & $34(56.67 \%)$ \\
\hline 3 & $08(26.66 \%)$ & $12(40.00 \%)$ & $20(33.33 \%)$ \\
\hline
\end{tabular}

Origin: In the present study, nerve to medial head of gastrocnemius arose independently from the main trunk in $42(70 \%$ ) limbs (20 on right and 22 on left).

It shared common stem with lateral head of gastrocnemius (Fig 1) in 6 out of $60(10 \%)$ limbs (3 on right and 3 on left). In 12 (20\%) limbs (7 on right and 5 on left), the nerve shared common origin with sural nerve. (Fig 2).

Table 2: Percentage distribution of mode of origin of $\mathrm{N}$. to medial head of gastrocnemius $(\mathrm{G})$.

\begin{tabular}{|c|c|c|c|}
\hline \multirow{2}{*}{ Mode of origin } & \multicolumn{3}{|c|}{ No. of limbs with particular mode of } \\
& \multicolumn{3}{|c|}{ origin [n (\%)] } \\
\cline { 2 - 4 } & Right & Left & Total \\
& $30(100 \%)$ & $30(100 \%)$ & $60(100 \%)$ \\
\hline Independent branch & $\begin{array}{c}20 \\
(66.66 \%)\end{array}$ & $\begin{array}{c}22 \\
(73.33 \%)\end{array}$ & $42(70 \%)$ \\
\hline Common trunk with N. to lat. head of G & $\begin{array}{c}03 \\
(10.00 \%)\end{array}$ & $\begin{array}{c}03 \\
(10.00 \%)\end{array}$ & $06(10.00 \%)$ \\
\hline Common trunk with sural N. & $\begin{array}{c}07 \\
(23.33 \%)\end{array}$ & $\begin{array}{c}05 \\
(16.66 \%)\end{array}$ & $12(20.00 \%)$ \\
\hline
\end{tabular}

\section{Nerve to lateral head of gastrocnemius}

Number: In the present study, the number of branches of nerve to lateral head of gastrocnemius was highly variable. It was 1 in 34 out of 60 (56.66\%) limbs (19 on right and 15 on left), 
2 in 21 out of 60 (35\%) limbs (10 on right and 11 on left) and 3 in 5 out of 60 (8.33\%) limbs (1 on right and 4 on left).

Table 3: Percentage distribution of number of Ns. to lateral head of gastrocnemius $(G)$.

\begin{tabular}{|c|c|c|c|}
\hline \multirow{2}{*}{$\begin{array}{l}\text { No. of } \\
\text { nerves }\end{array}$} & \multicolumn{3}{|c|}{ No. of limbs with particular no. of Ns. [n (\%)] } \\
\hline & $\begin{array}{c}\text { Right } 30 \\
(100 \%)\end{array}$ & $\begin{array}{l}\text { Left } 30 \\
(100 \%)\end{array}$ & $\begin{array}{c}\text { Total } 60 \\
(100 \%)\end{array}$ \\
\hline 1 & $\begin{array}{c}19 \\
(63.33 \%)\end{array}$ & $15(50.00 \%)$ & $34(56.66 \%)$ \\
\hline 2 & $\begin{array}{c}10 \\
(33.33 \%)\end{array}$ & $11(36.66 \%)$ & $21(35.00 \%)$ \\
\hline 3 & $\begin{array}{c}01 \\
(3.33 \%)\end{array}$ & 04(13.33\%) & 05(08.33\%) \\
\hline
\end{tabular}

Origin: In the present study, nerve to lateral head of gastrocnemius arose independently in 40 (66.66\%) limbs (20 on right and 20 on left).It shared common stem with nerve to medial head of gastrocnemius in 6 out of $60(10 \%)$ limbs (3 on right and 3 on left). It shared common stem with other muscular branches like nerve to soleus (Fig 3 ) in 10 (16.66\%) limbs (5 on the right and 5 on the left) and with nerve to plantaris (Fig 4) in 4 (6.67\%) limbs (2 on right and left each).

Table 4: Percentage distribution of mode of origin of nerve to lat. head of gastrocnemius (G).

\begin{tabular}{|c|c|c|c|}
\hline \multirow{2}{*}{ Mode of origin } & \multicolumn{3}{|c|}{ No. of limbs with particular mode of origin } \\
& [n (\%)] \\
\cline { 2 - 5 } & $\begin{array}{c}\text { Right 30 } \\
(100 \%)\end{array}$ & $\begin{array}{c}\text { Left 30 } \\
(100 \%)\end{array}$ & $\begin{array}{c}\text { Total 60 } \\
(100 \%)\end{array}$ \\
\hline Independent trunk & $20(66.66 \%)$ & $20(66.66 \%)$ & $40(66.66 \%)$ \\
\hline Common trunk with N. to med. head of G & $03(10.00 \%)$ & $03(10.00 \%)$ & $06(10.00 \%)$ \\
\hline Common trunk with N. to soleus & $05(16.66 \%)$ & $05(16.66 \%)$ & $10(16.66 \%)$ \\
\hline Common trunk with N. to plantaris & $02(6.67 \%)$ & $02(6.67 \%)$ & $04(6.67 \%)$ \\
\hline
\end{tabular}

Fig. 1: Nerve to medial head of gastrocnemius sharing common stem with nerve to lateral head of gastrocnemius.

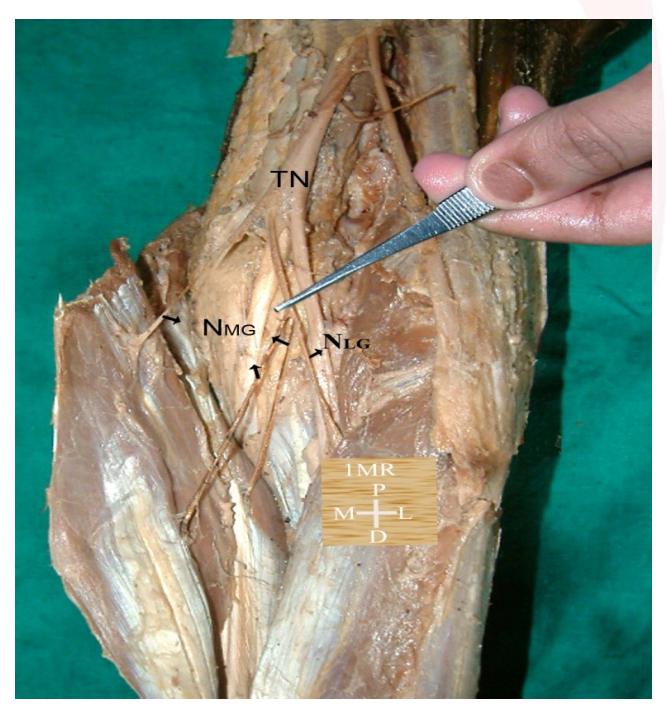

Fig. 2: Nerve to medial head of gastrocnemius sharing common stem with sural nerve.

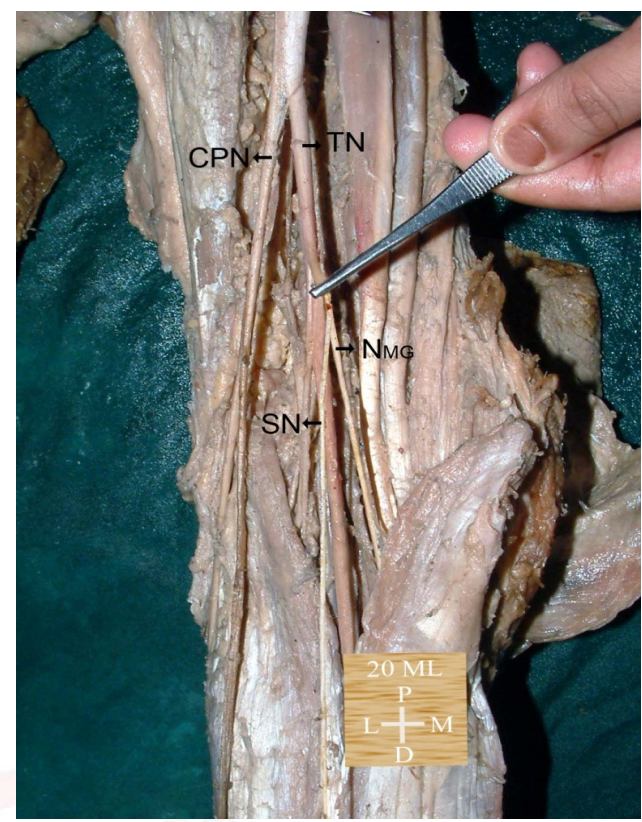

Fig. 3: Nerve to lateral head of gastrocnemius sharing common stem with nerve to soleus.

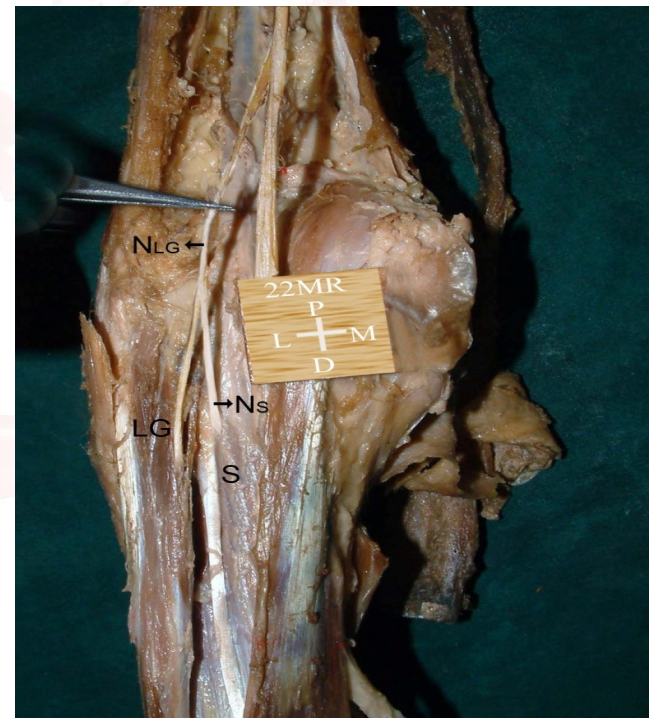

Fig. 4: Nerve to lateral head of gastrocnemius sharing common stem with nerve to plantaris.

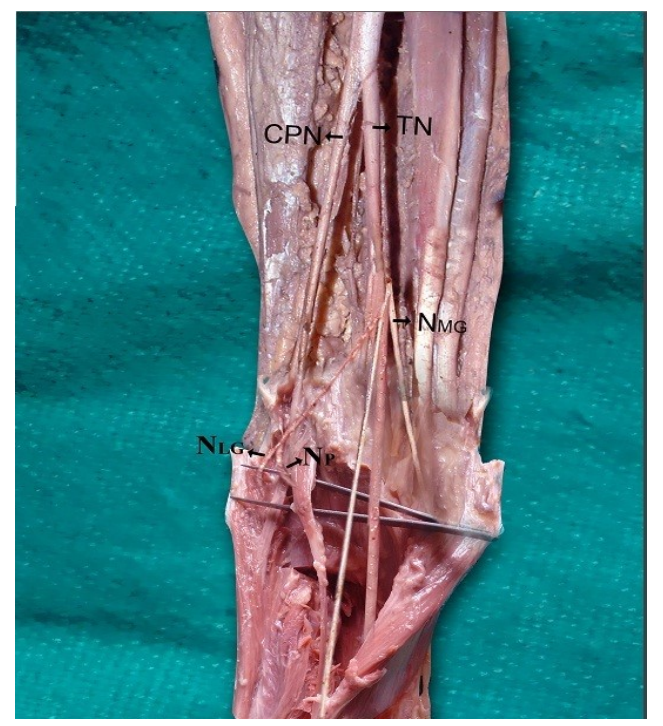




\section{DISCUSSION}

The origin and number of nerve to medial and lateral gastrocnemius is highly variable in present study although it is documented by a few authors.

Wongphaet et al [3] dissected 62 legs and found that there was 1 branch to medial head of gastrocnemius in 44 (70.96\%) limbs, 2 branches in 14 (22.58\%) limbs and 3 branches in 4 (6.45\%) limbs.

According to Liu et al [4], in $60 \%$ limbs there was 1 branch and in $40 \%$ limbs there were 2 branches to medial head of gastrocnemius, which is in near perfect agreement with that of present study.

Sunderland and Hughes [5] found nerve to the two heads sharing stem in 2 out of 20 specimens i.e. $10 \%$, which is in consonance with that of present study.

Table 5: Comparison of number of nerves to medial head of gastrocnemius $(\mathrm{G})$.

\begin{tabular}{|c|c|c|c|c|c|}
\hline \multirow{2}{*}{ Author } & \multirow{2}{*}{ Year } & \multirow{2}{*}{$\begin{array}{c}\text { No. of } \\
\text { limbs }\end{array}$} & \multicolumn{3}{|c|}{$\begin{array}{c}\text { No. of limbs with particular no. of } \\
\text { studied }\end{array}$} \\
\cline { 4 - 6 } & & & 1 & 2 & 3 \\
\hline Wongphaet et al [3] & 2005 & 62 & $\begin{array}{c}44 \\
(70.96 \%)\end{array}$ & $\begin{array}{c}14 \\
(22.58 \%)\end{array}$ & $\begin{array}{c}4 \\
(6.45 \%)\end{array}$ \\
\hline Liu et al [4] & 2007 & 20 & $\begin{array}{c}12 \\
(60 \%)\end{array}$ & $\begin{array}{c}08 \\
(40 \%)\end{array}$ & - \\
\hline Present study & 2017 & 60 & $\begin{array}{c}34 \\
(56.67 \%)\end{array}$ & $\begin{array}{c}20 \\
(33.33 \%)\end{array}$ & $\begin{array}{c}06 \\
(10 \%)\end{array}$ \\
\hline
\end{tabular}

According to Liu et al [4] in 30\% cases, the medial sural cutaneous nerve originated from nerve to medial head of gastrocnemius which is in near agreement with the present study.

Wongphaet et al [3] dissected 62 legs and found that there was 1 branch to lateral head of gastrocnemius in 45 legs (73.77\%), 2 branches in 13 legs (21.31\%) and 3 branches in 3 legs (4.92\%).

According to Hollinshead [6] either head of muscle may receive more than one branch.

Sunderland and Hughes [5] found nerve to the two heads sharing stem in 2 out of 20 specimens i.e. $10 \%$, which is in consonance with that of present study.

Immediate facial nerve reconstruction is very demanding after total parotidectomy. Under such conditions facial nerve is being reconstructed by using vascularized sural nerve with free lateral gastrocnemius muscle flap [7].

In Orientals, hypertrophy of calves frequently found. Calf muscles composed of the medial, lateral gastrocnemius and soleus muscles. To identify the muscle hypertrophy clinically, the patient should stand on toe-tip posture and check out the pinch test for the measurement of fat thickness. Muscular hypertrophy of the calves is divided into 3 types, such as medial

Table 6: Comparison of mode of origin of nerve to medial head of gastrocnemius (G).

\begin{tabular}{|c|c|c|c|c|c|}
\hline & \multirow{2}{*}{ Author } & \multirow{2}{*}{$\begin{array}{c}\text { No. of } \\
\text { limbs }\end{array}$} & \multicolumn{2}{|c|}{ No. of limbs with particular mode of origin [n (\%)] } \\
\cline { 5 - 6 } & Year & $\begin{array}{c}\text { Independe } \\
\text { studied }\end{array}$ & $\begin{array}{c}\text { Common trunk with } \\
\text { nt branch }\end{array}$ & $\begin{array}{c}\text { Common trunk } \\
\text { nerve to lat. head of G }\end{array}$ & with sural nerve \\
\hline Sunderland and Hughes [5] & 1946 & 20 & $18(90 \%)$ & $02(10 \%)$ & - \\
\hline Liu et al [4] & 2007 & 20 & $14(70 \%)$ & - & $06(30 \%)$ \\
\hline Present Study & 2017 & 60 & $42(70 \%)$ & $06(10 \%)$ & $12(20 \%)$ \\
\hline
\end{tabular}

Table 7: Comparison of number of Ns. to lateral head of gastrocnemius (G).

\begin{tabular}{|c|c|c|c|c|c|}
\hline \multirow{2}{*}{ Author } & \multirow{2}{*}{ Year } & \multirow{2}{*}{$\begin{array}{c}\text { No. of } \\
\text { limbs } \\
\text { studied }\end{array}$} & \multicolumn{3}{|c|}{ No. of limbs with particular no. of Ns. [n (\%)] } \\
\cline { 4 - 6 } & & 62 & $45(73.77 \%)$ & $13(21.31 \%)$ & $03(04.92 \%)$ \\
\hline Wongphaet et al [3] & 2005 & 60 & $34(56.66 \%)$ & $21(35.00 \%)$ & $05(08.33 \%)$ \\
\hline Present study & 2017 & 62 & $\mathbf{3}$ \\
\hline
\end{tabular}

Table 8: Comparison of mode of origin of nerve to lateral head of gastrocnemius (G).

\begin{tabular}{|c|c|c|c|c|c|c|}
\hline \multirow[b]{2}{*}{ Author } & \multirow[b]{2}{*}{ Year } & \multirow{2}{*}{$\begin{array}{l}\text { No. of } \\
\text { limbs } \\
\text { studied }\end{array}$} & \multicolumn{4}{|c|}{ No. of limbs with particular mode of origin [n (\%)] } \\
\hline & & & $\begin{array}{l}\text { Independent } \\
\text { trunk }\end{array}$ & $\begin{array}{l}\text { Common trunk with nerve } \\
\text { to med. head of G. }\end{array}$ & $\begin{array}{c}\text { Common trunk } \\
\text { with nerve to } \\
\text { soleus }\end{array}$ & $\begin{array}{c}\text { Common trunk } \\
\text { with nerve to } \\
\text { plantaris }\end{array}$ \\
\hline Sunderland and Hughes [5] & 1946 & 20 & $18(90.00 \%)$ & $02(10.00 \%)$ & - & - \\
\hline Present Study & 2017 & 60 & $40(66.66 \%)$ & $06(10.00 \%)$ & $10(16.66 \%)$ & $04(06.67 \%)$ \\
\hline
\end{tabular}


upper half, lateral upper half and total hypertrophy with or without excess fat of lower legs. The indications of calves reduction depends on the excess fat of lower leg, calf muscle hypertrophy and combined excess fat and muscle hypertrophy. The methods of calf reduction are weight control, liposuction, calf muscle resection and combined procedures. But the postoperative results are not as dramatic as abdomen and have low satisfaction rate because there are many postoperative complications, such as surface irregularities, asymmetrical shape, scars with hyper pigmentation and infection. So neurectomy of medial gastrocnemius muscle is the new ideal method for calf muscle hypertrophy [8].

To reduce the volume of medial gastrocnemius for calf reduction, neurectomy of nerve to medial gastrocnemius muscle was safe and effective method. Neurectomy of nerve to medial gastrocnemius muscle was performed in 16 cases as stated by Liu et al. After operation the circumference of leg was reduced by $3.5+/-1.1$ $\mathrm{cm}$ averagely and curve of medial line of calf was reduced. There was no obvious swelling in these cases and patient was able to walk immediately after operation [4].

Selective neurectomy of the innervating nerves of the gastrocnemius muscle is a popular method employed for calf reduction. However, accidental variety of origin patterns among the nerves to the lateral and medial gastrocnemius muscle, the nerve to the soleus muscle and the sural cutaneous nerve exist, necessitating the formulation of diversifying surgical strategies preoperatively and the meticulous and sequential dissection intra-operatively to ensure the lowest level of accidental injury. Injury to the untargeted adjacent nerves could happen [9].

\section{Conflicts of Interests: None}

\section{REFERENCES}

[1]. Williams P L, Bannister LH, Berry MM, Collins P, Dyson M, Dussek LE et al. The Lower Limb. Berry MM, M standring S, Bannister LH. In: Gray's Anatomy. $40^{\text {th }}$ Edition. Edinburgh, London: Churchill Livingstone; 2008; 1420-1421.

[2]. Romans GJ. The popliteal fossa, back of thigh, leg and foot. In: Cuningham's Manual of Practical Anatomy. $15^{\text {th }}$ Edition. Edinburgh, London: Book Society and Oxygen University Press; 1986; (3): 160214.

[3]. Wongphaet $P$, Chinsethagij K, Suarchawaratana $S$, Dangprasert $T$, Wongphaet $W$. Precise localization of motor branching and motor points : a cadaveric study. J med assoc Thai 2005; 88(12): 1884-1891.

[4]. Liu DL, Li XI, Shan L, Li Q, Yuan JL, Yuan Q. The anatomic study and clinical observation of neurectomy of nerve to medial gastrocnemius muscles for calf reduction. Zhonghua Zheng Xing Wai Ke Za Zhi 2007; 23(2): 125-127.

[5]. Sunderland $S$, Hughes. Metrical and non metrical features of muscular branches of sciatic nerve and its medial and lateral popliteal division. J Comp neurol 1946; 85: 205. Cited by Hollinshead WH. Knee, Leg, Ankle and Foot. In: Anatomy for surgeonsthe back and limbs. $1^{\text {st }}$ Edition. New York: Paul B Hoeber Inc. Med Book deptt. of Harper and Brothers; 1958; (3): 818-821.

[6]. Hollinshead WH. Knee, Leg, Ankle and Foot. In: Anatomy for surgeons- the back and limbs. $1^{\text {st }}$ Edition. New York: Paul B Hoeber Inc. Med Book deptt. of Harper and Brothers; 1958; (3): 818-821.

[7]. Ikou H, Taijiro O, Yasuhisa H, Tetsuya O, Akihiro T, Shuhei T. Management of a total parotidectomy defect with a gastrocnemius muscle transfer and vascularized sural nerve grafting. Ann of Plastic Surg 2007;58(6): 677-682.

[8]. Suh IS. Neurectomy of Nerve Branch to Medial Gastrocnemius Muscle for Calf Reduction. J Korean Soc Aesthetic Plast Surg 2007 Sep 13(2):95-104.

[9]. Wang HB, Lin SQ, Xu DC, Sun ZS, Xu X, Wen GM et al. Anatomic study of selective neurectomy of gastrocnemius muscle for calf reduction in Chinese. J Plast Reconstr Aesthet Surg. 2013 Jun; 66(6):e162-5.

How to cite this article: Sharma S, Khullar M, Wadhwa A, Kaur

$K$, Bhardwaj S, Sharma N. VARIATION IN THE MODE OF ORIGIN AND LEVEL OF FORMATION OF NERVE TO MEDIAL AND LATERAL HEAD OF GASTROCNEMIUS MUSCLE. Int J Anat Res 2020;8(1.1):7232-7236. DOI: 10.16965/ijar.2019.346 